\section{INFLUENCE OF THE MILK SUPPLY ON THE SPREAD OF TUBERCULOSIS,}

\section{BASED UPON AN INVEGTIGATION OF SIXTEGN MILK} SUPPIIES IN CAMBRIDGE.

BY THE LA'T A. A. KANTHACK, M.A. M.D., F.R.C.P. LOND.,

FELTOW OF KING'S COLLEGE AND PROFESSOR OF PATHOLOGY IN THE UNIVERSITY OF CAMBRIDGE ;

\section{AND}

B. SYDNEY St. B. SLADEN, M.A., B.C., M.D. CANTAB.

1. Introduction.-Last April Professor Kanthack suggested as a subject for research the study of the effect upon the spread of tuberculosis prodnced by the various milk supplies to the different colleges in Cambridge. He very kindly offered his assistance; it is therefore under his guidance and with his help and advice that the following record of results has been compiled. This paper is limited to a narrative of our joint work-the investigation of the tuberculous lesions and the presence of the tubercle bacillus found in guineapigs as the result of inoculation of milk, no notice being taken of other points of interest outside the immediate subject; this is due to the fact that the present article (though complete in itself) is only a preliminary paper. We are now carrying out a further and exhaustive investigation on the milk supplies in Cambridge leading, we hope, to the possibility in the near future of buying milk which comes from cows certified to be free from tuberculosis. Experience and observation have convinced us that infantile tuberculosis is by no means uncommon in Cambridge; and since the danger now generally recognised abroad of spreading tuberculosis by milk is gradually being appreciated in this country all that is needed is to rouse people at home to the consciousness of this danger and make them understand that it is their duty to insist on being supplied with milk free from tuberculous infective material. Similar investigations have been made in other parts of the world and they are already bearing fruit. We may thus mention the work of Professor Bang of Copenhagen, of Professor Delépine in Manchester, and the well-known researches of the Royal Commission. Professor Delépine's work has already induced Lord Vernon to follow the example set by the Danes and Germansramely, to stamp out tuberculosis in his own herds. We hope that once the colleges have recognised the true state of affairs they will insist on obtaining a pure milk supply and will assist the dairymen in bringing about improved conditions. The manner in which this may be done will be fiscussed in the fuller report which unfortunately has been delayed by Professor Kanthack's illness. The object of this paper is to set forth the evidence upon which the fuller report is mainly based. To collect such evidence is a matter of some difficulty and at any rate requires a considerable amount of time and labour. It may be noted that Professor Kanthack saw every animal which was dissected and in every instance the diagnosis was accepted and confirmed by him before it was placed on the records.

2. Method of work.--Early in May arrangements were made as regards collection of the milk and a regular supply of healthy guinea-pigs. During the first three days only 12 guinea-pigs were inoculated, 4 each day; afterwards, when a routine method had been devised, the number was increased to 6 each day, and this number was adhered to throughout the remainder of the work. It was decided to inoculate 2 guinea-pigs with each sample of milk and to continue this for two successive days, using fresh guineapigs each day, so that each separate supply was thus passed through 6 guinea-pigs ; the only exception to this arrangement was H.'s supply, which was inoculated into 4 guinea-pigs owing to forgetfulness on the part of one of the college porters to have the bottle left with him filled with milk. It was found more convenient to use the morning delivery of milk in place of that obtained in the afternoon owing to the work sometimes occupying much time. Thus, although more time was lost between collection and inoculation, still by putting off the staining of any coverglass preparations until after all the inoculations had been made this loss of time was inconsiderable. Some of the samples of milk were collected as early as 6 A.M. and as it was impossible to start work before 9 A.M. some time elapsed before the inoculations could be made, the greatest difference between the time of collection and inoculation being four hours and the smallest being fifteen minutes; an average taken of all the experiments shows the difference to be just under two hours. This, however, is immaterial since we are here dealing with the tubercle bacillus only.

3. Method of collection of the milk.-(a) A glass-stoppered bottle, having been well washed, done up in paper, and tied with string, was placed in the steriliser and sterilised half an hour at a temperature of $115^{\circ} \mathrm{C}$. (b) The bottle when cold was usually taken to a college (the permission of the college authorities having been previously obtained) and left with the porter or at the kitchen some hours before the particular milkman arrived. (c) In the presence of the milkman the bottle was opened and then filled by the milkman direct from his can; it was immediately shut again, done up in paper, and tied with string; the milkman's name was then written on the paper covering the bottle. Thus the milk, as it was received for examination at the Pathological Laboratory, was in exactly the same condition as that in which it was while in the milkman's can, the only difference being in respect of the time lapsing between collection and examination. The milk was of course "mixed"-i.e., derived from different cows. Later, it is intended to examine the milk from individual cows in order to gain an idea as to how many cows proportionately are tuberculous. Here we are dealing with the question of the milk-supply generally and it is our intention to go no further in this paper than the investigation of the "mixed" milk of each supplier.

4. Method of inoculation.-Previously to all inoculations all instruments and vessels had been sterilised by heat and after each operation were at once placed in strong lysol solution, so that it was quite impossible that these could be held liable for any accidental infection with tubercle bacilli. A fresh syringe and needle, both carefully sterilised, were also employed for each separate sample of milk. With the exception of two cases each inoculation was made into the right groin of a guinea-pig. Two glass tubes of a Metzger centrifugal machine were filled up to the 10 c.c. mark with milk taken from each sample, these were then centrifugalised for five minutes, the time being always accurately kept by reference to a clock placed just over the centrifugalising. machine. This machine was usually worked at the rate of from 3000 to 4000 revolutions per minute. The average yield of cream from 10 c.c. of milk after centrifugalisation was found to be 0.93 c.c. Later in this paper it is stated that 3 c.c. of the "creamy layer" were inoculated-that is to say, as much cream as possible was collected from each. of the two glass tubes, the remainder being made up of the milk floating next to the cream. The "sediment" refers to the deposit found at the bottom of the glass tube; to this part all solid particles should have been driven, but as will be noticed later this does not apply to all the tubercle bacilli when present in milk-some remain in the sediment, but a considerable number are carried up and remain in the creamy layers. Two guinea-pigs were then inoculated, one with the creamy layer, another with the milk at the bottom of the glass tube.

The following is an example of the method employed for each sample of milk, being taken from notes recording the inoculations of the 67th and 68th guinea-pigs : 1 . Time of reception of milk from dairyman, 4 P.M. 2. Time of centrifugalisation (two tubes each containing 10 c.c.) 4.30 P.M o 3. Yield of cream after centrifugalisation from one tube, 0.25 c.c. 4 . (a) 3 c.c. of creamy layer (taken from the two tubes) were inoculated into the right groin of one guinea-pig. (Label L, 67 a.) Rough haired, fawn and white. (b) 3 c.c. of sediment were inoculated into the right groin of another guinea-pig. (Label L, 68 b.) Black and fawn. 5. Coverglass preparations were then made from the sediment which, after allowing sufficient time for drying in the air, were stained by carbolised fuchsin and counter-stained by methylene blue in the usual way in order to differentiate the tubercle bacillus from other bacilli.

On examination with the aid of a 1 oil immersion the results were: (a) cocci and diplococci, but only few in number; and $(b)$ tubercle bacilli (two present in one preparation). The amount inoculated, ranging from 1.5 c.c. to 3 c.c., was determined in accordance with the size of the guineapig; if of large size then 3 c.c. were used. An average of all 
the quantities inoculated gives this result: 2.4 c.c. for the oreamy layer, $2 \cdot 1 \mathrm{c.c}$. for the sediment. In the guinea-pigs that died from tuberculosis the average amount inoculated was 2.28 for the creamy layer and 2.07 for the sediment.

5. Method of kepping animals under observation.-For the first three days all the guinea-pigs inoculated on those days were kept in one cage, having celluloid labels fastened by lead wire round their necks (a contrivance which Dr. L. Cobbett very kindly suggested). Besides this means of recognition a detailed account of the colours and peculiarities of the guinea-pig was made in case the labels should chance to get lost. When the cages contained 18 guinea-pigs each group of 6-i.e., each group of animals belonging to each dairywas picked out and placed in a separate cage, the labels being afterwards removed, and this method was adhered to to the end of the investigation. The guinea-pigs were kept in the country under the best possible conditions and were examined twice a week. After having been under observation for several weeks, when any showed marked enlargement of the inguinal glands, these were killed by ether or chloroform.

6. Method of examining the guinea-pigs.--Each guinea-pig after death was carefully opened and examined for any signs of tuberculosis. If any signs of tuberculosis were present they were noted and a general description written down. Cover-glass preparations were at once made, the part to be stained being taken from an abscess or a nodule in the spleen or a caseous lymphatic gland; these were stained for tubercle bacilli in warm carbol fuchsin, passed rapidly through $\mathrm{HCl}(1$ in 4$)$ decolourised in 70 per cent. of methylated spirit and counted-stained with methylene blue. Parts of the spleen, liver, lungs, and glands were then bottled in Müller's fluid, a label being placed on the bottle. When hardened sufficiently small portions were removed and embedded in paraffin. Four sets of sections were stained, two with hæmatein and eosin, and two others (as above) for tubercle bacilli. In many cases several sets had to be cut and stained before positive results could be obtained. This is important because it is known that in milk and especially in butter pseudo-tubercle bacilli may occur which in the guinea-pigs produce lesions macroscopically resembling tubercle, but microscopically differing from the true tubercle, in that the histological elements of tubercle are absent. Cultures were not made from the various organs, since this is very laborious, difficult, and uncertain ; and the other tests taken altogether were sufficient to establish a correct diagnosis. By microscopic examination out of the 33 guinea-pigs suspected of having contracted tuberculosis 10 were found to be not affected with tuberculosis, 23 showed typical histological tuberculous lesions, whilst in 16 of the 23 the tubercle bacillus was plainly demonstrated.

Following the example of those who made experiments upon guinea-pigs for the Royal Commission on Tuberculosis and discarded from their results all guinea-pigs which died within twenty-one days of inoculation we have deducted 4 guinea-pigs from the total number inoculated; these died as follows: $(a)$ one on the first day after inoculation (b) one on the second day after inoculation; $(c)$ one on the third day after inoculation; and $(d)$ one on the fifth day after inoculation. Three out of the four belong to groups in which two or more eventually became affected with tuberculosis due to inoculation of milk, thus $(a)$ belonged to a group in which 2 out of 6 died from tuberculosis; (b) belonged to a group in which 2 out of 6 died from tuberculosis; and (d) belonged to a group in which 4 out of 6 died from tuberculosis. It is reasonable to suppose that had they lived one or more of these guinea-pigs might have come under the heading of those that died from tuberculosis.

It has been found necessary to deduct a whole groupnamely, $K$. It was noticed at the time of inoculation that $K$ bore the name of the same dairy as $\mathrm{C}$, and, later, postmortem examinations and the construction of the tables of results disclosed the fact that two guinea-pigs, one from $\mathrm{O}$ and one from $\mathrm{K}$, showed similar internal lesions. This led to an inquiry being made as regards the dairy, when it was found that the same milkman supplied the two colleges. Therefore out of the 100 guinea-pigs originally inoculated the following have been deducted: (a) four that died within twenty-one days of inoculation; and (b) six that belonged to group $K$, which subsequently was found to be the same as C. 1hesults.-1. Of the 90 guinea-pigs inoculated 23 died from tuberculosis giving a percentage of $25 \cdot 55$. Of these 23 guinea-pigs, 13 were inoculated with the creamy layer and 10 with the sediment. 2. Of the 16 dairies examined the milk of 9 caused tuberculosis-i.e., the milk-supply of more than half of them was tainted and capable of spreading tuberculosis. These results may be given in tabular form.

\begin{tabular}{|c|c|c|c|}
\hline \multirow[t]{2}{*}{ Dairy. } & \multicolumn{2}{|c|}{$\begin{array}{c}\text { Number of guinea-pigs infected with } \\
\text { tuhercle as the result of inoculation } \\
\text { with- }\end{array}$} & \multirow{2}{*}{$\begin{array}{l}\text { Evidence of } \\
\text { tuliercle } \\
\text { lacilli in } \\
\text { the milk. }\end{array}$} \\
\hline & Creamy layer. & Sediment. & \\
\hline $\mathbf{A}$ & None & None & - \\
\hline B & 1 out of 3 & 1 out of 3 & + \\
\hline $\mathrm{C}$ & None & None & - \\
\hline D & 2 out of 3 & 3 out of 3 & + \\
\hline $\mathbf{E}$ & None & None & - \\
\hline $\mathbf{F}$ & 1 out of 3 & 1 out of 3 & + \\
\hline G & 1 out of 3 & None & + \\
\hline H & 1 out of 2 & 1 out of 2 & + \\
\hline I & None & None & - \\
\hline $\mathrm{J}$ & None & None & - \\
\hline $\mathbf{L}$ & 1 out of 3 & 2 out of 3 & + \\
\hline $\mathbf{M}$ & None & None & - \\
\hline$N$ & 2 out of 3 & 2 out of 3 & + \\
\hline o & None & None & - \\
\hline$P$ & 3 out of 3 & None & + \\
\hline$Q$ & 1 out of 3 & None & + \\
\hline
\end{tabular}

It is thus evident that more than balf of the 16 dairies examined now supplying ten of the colleges send out milk containing tubercle bacilli in sufficient quantities to cause tuberculosis in guinea-pigs when these animals have been subjected to inoculation; it is therefore not unreasonable to regard these dairies as a source of grave danger. Again, these dairies supply not only colleges but the town as well ; here the danger is much more marked as regards: (a) hand-fed infants; (b) young children; (c) delicate people; and $(d)$ all people suffering from acute diseases. In these cases a milk diet is often considered necessary, in some it is the sole diet. Some of these people cannot drink boiled milk and therefore it is most important that they should not use milk containing tubercle bacilli. Whilst some authorities consider tuberculosis to arise solely from inhaled tubercle bacilli, it is probable that a very much larger number of human beings, and certainly of infants, contract that disease by drinking milk containing living tubercle bacilli.

Now it may be argued that almost half the dairies of Cambridge supply milk free from tubercle bacilli. Such argument would be extremely unsafe, for $(a)$ before we can speak favourably of a dairy we should have to examine every animal separately; and $(b)$ a dairy which three successive days sends out milk free from tubercle bacilli a few days later may issue milk containing these bacilli. The fact that more than half the dairies examined sell milk containing living tubercle bacilli shows how serious the matter is at the present time. Therefore if we are asked how to avoid all danger of infection we answer-(a) under existing conditions nothing but boiled or carefully sterilised milk should be consumed; and $(b)$ cream, unless obtained after boiling or scalding, should not be given to infants or delicate persons. Ideal conditions demand that we should not rest content with anything short of the certainty that no milk is offered for sale except that obtained from cows known to be free from tuberculosis. We must in fact aim at introducing the system which Professor Bang has so successfully carried out in Denmark; at any rate, it is our duty to protect those who cannot protect themselves.

The accompanying tables give the symbol for each dairy, the number of the experiment, and the quantity of cream or sediment inoculated; they show whether the guinea-pig died or was killed and how many days occurred between inoculation and death. The macroscopic and microscopic examinations are found in columns i. to xvi. The remarks at the foot of the tables, containing the combined results of macroscopic and microscopic examinations, give the details 
76 The LANCET,] DRS. KANTILACK \& SLADEN: MILK-SUPPLY AND SPREAD OF TUBERCULOSIS. [J $\mathrm{J}_{\text {N. }}$. 14; 1899.

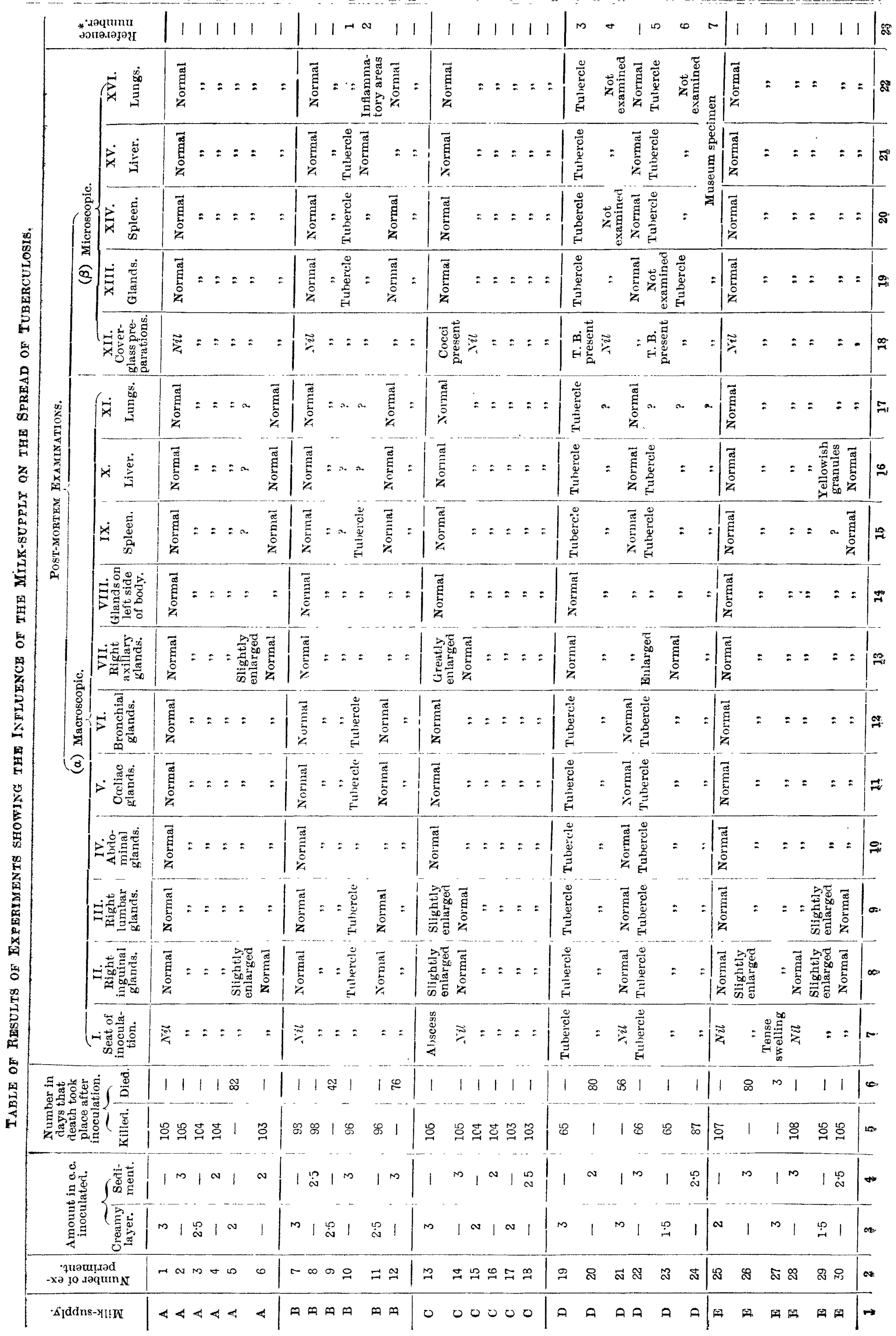


THE LANCET,] DRS. KANTHACK \& SLADLN: MILK-SUPPLY AND SPREAD OF TUBERCULOSIS. [JAN. 14, 1899.77

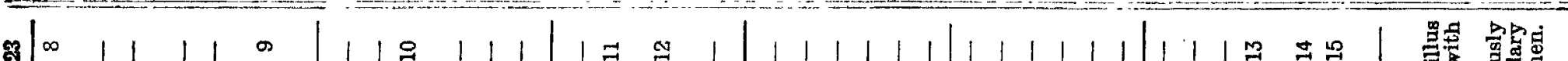

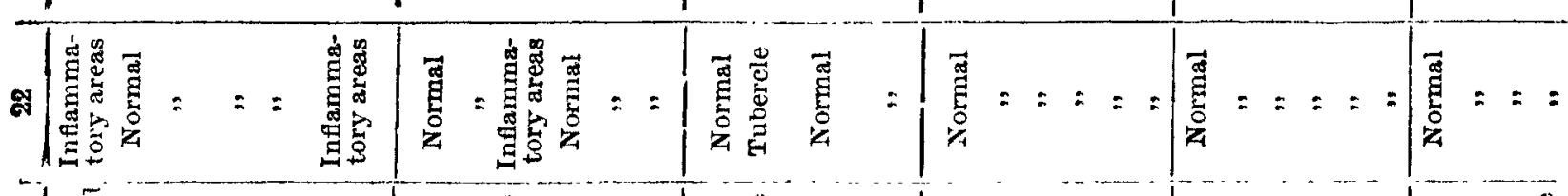

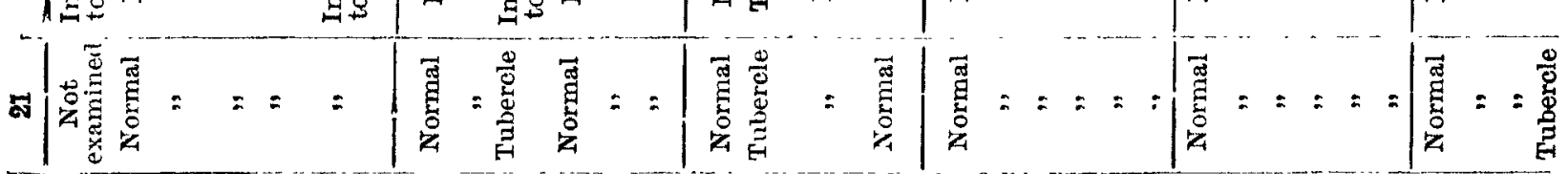

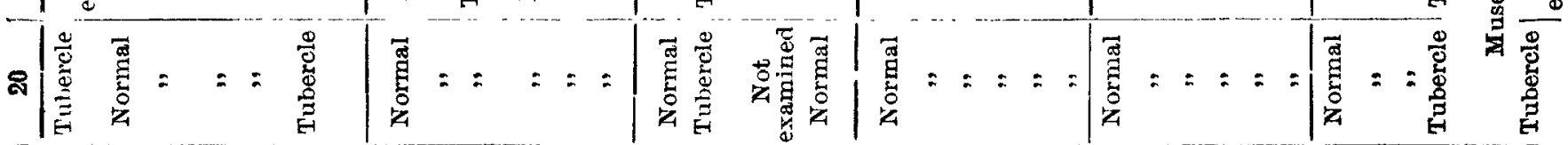

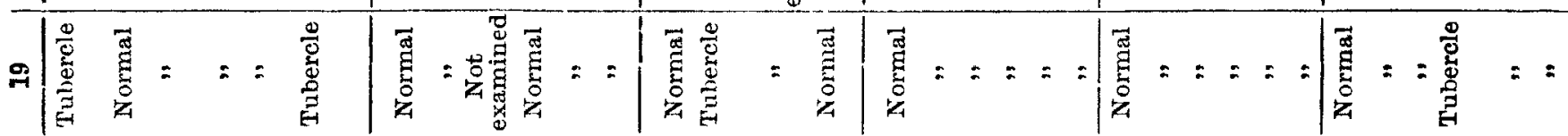

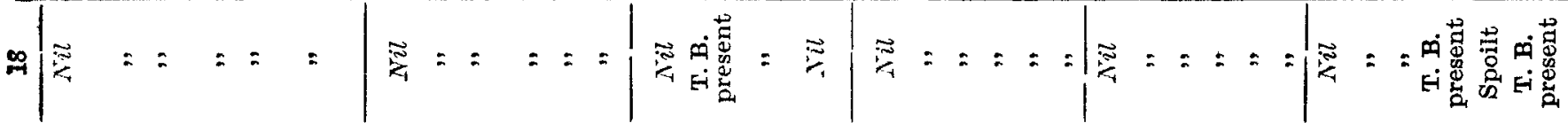

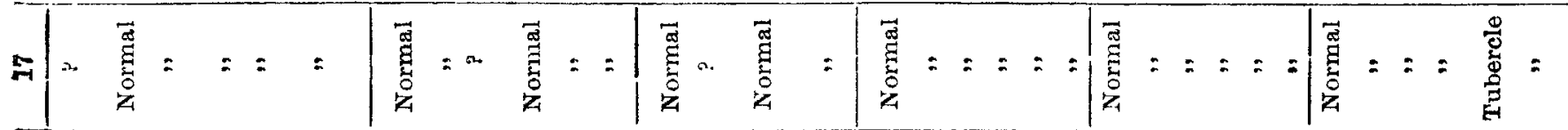

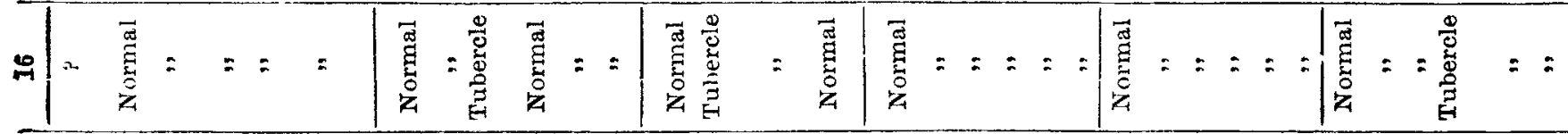

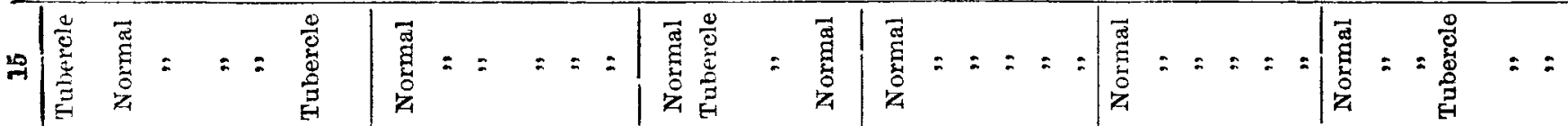

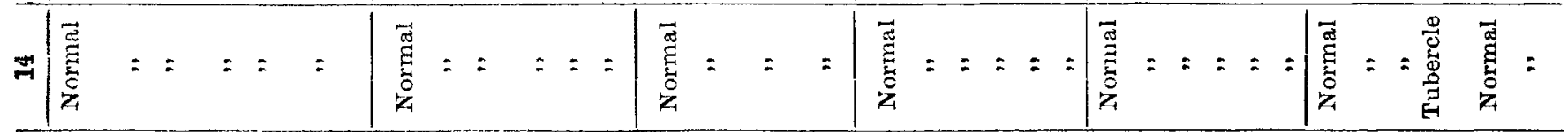

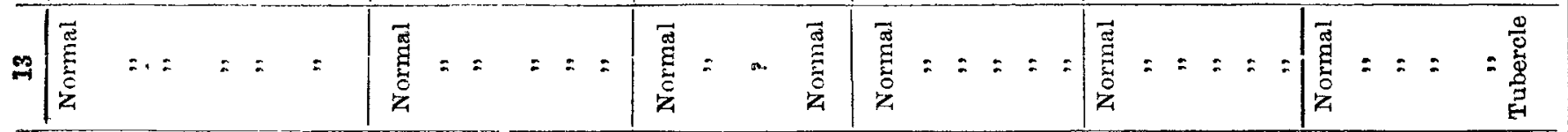

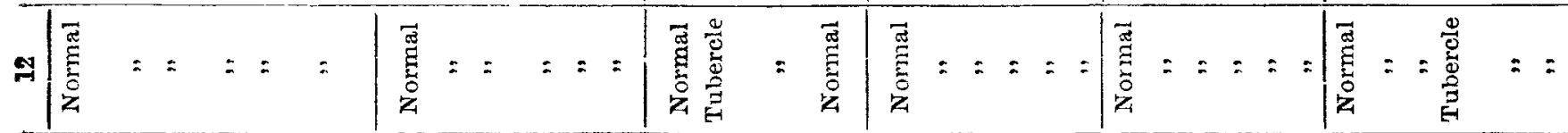

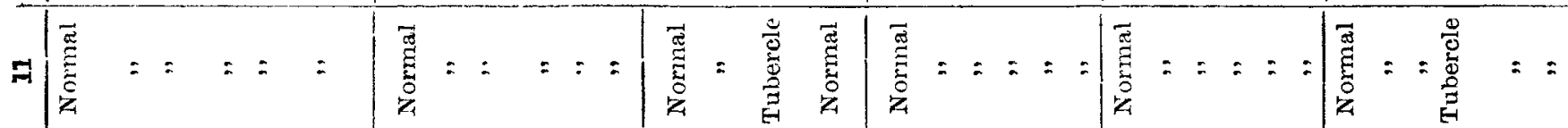

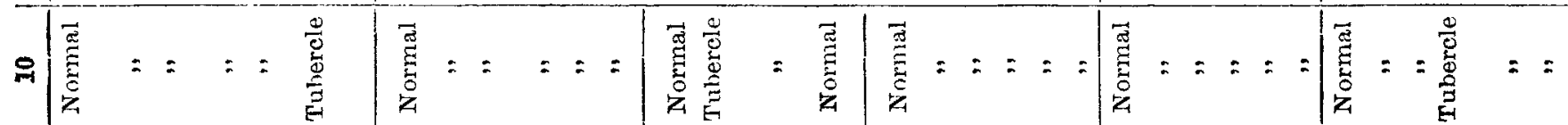

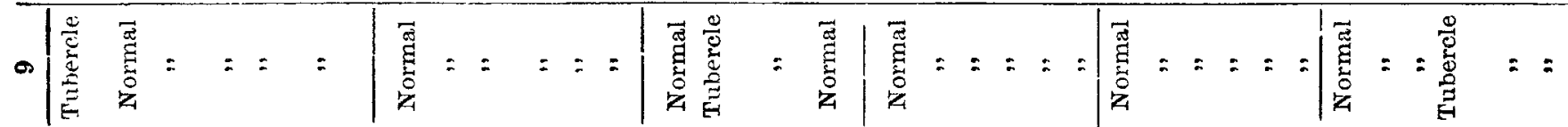

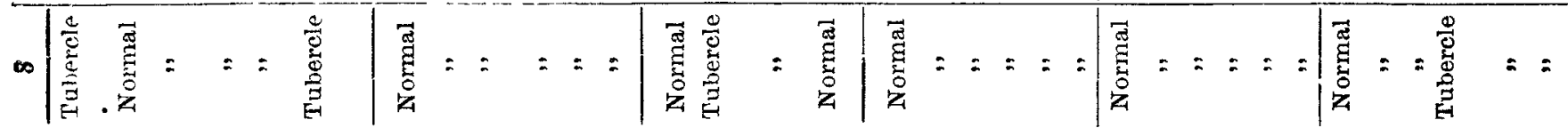

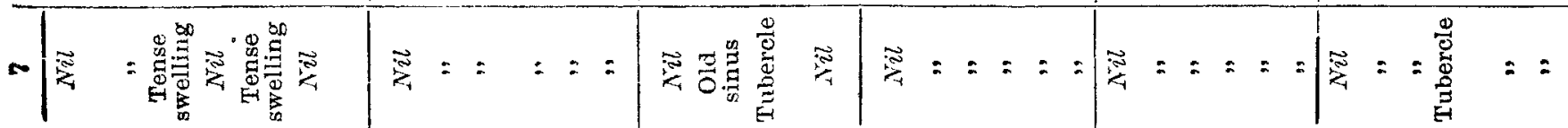

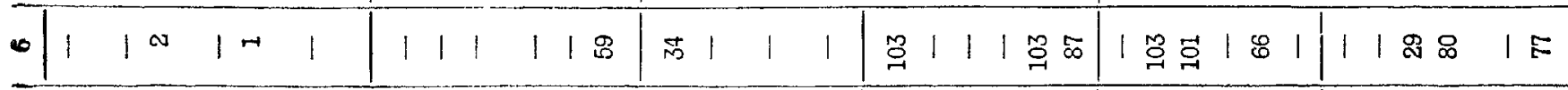
4|붕

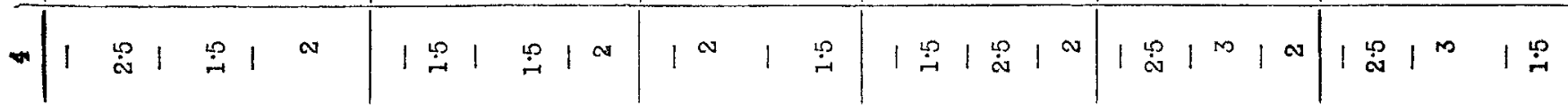

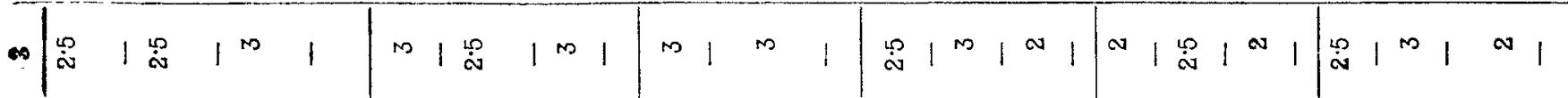

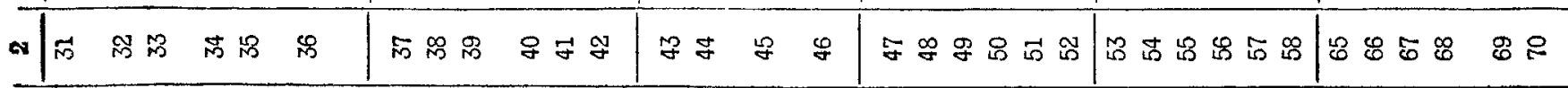

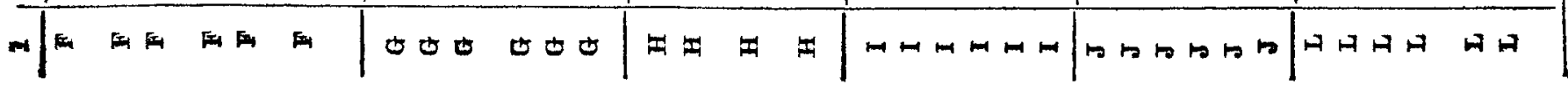




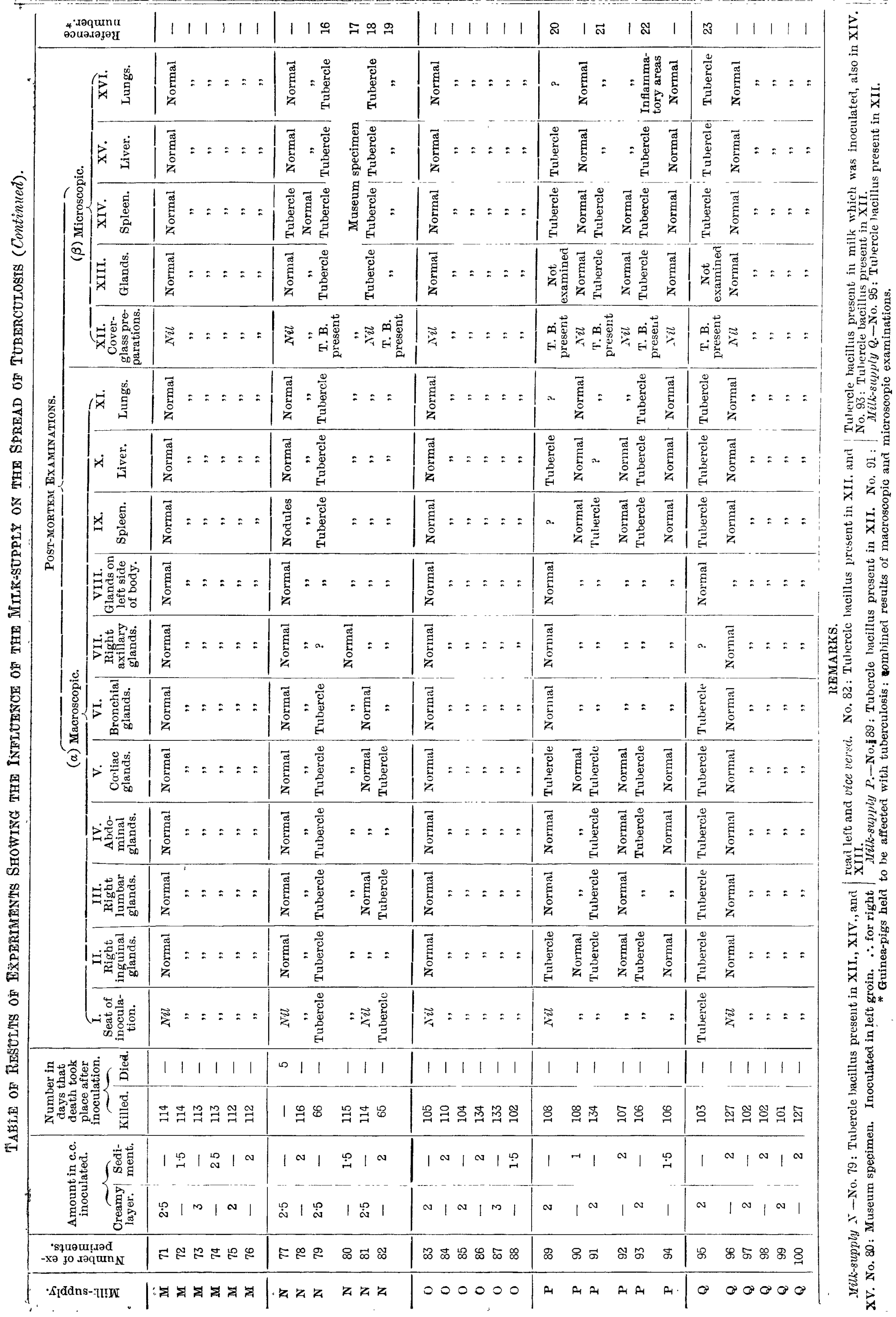


of guinea-pigs which were found to be affected by tuberculosis.

[We have left this paper as it reached us, and it will be seen that it was written before the lamented deaths of Professor Kanthack and Lord Vernon. Professor Kanthack, realising that the "fuller report" alluded to would never be written, expressed a wish on Dec. 15th last that the results of the investigation up to date should be published in the joint names of Dr. Sladen and himself.-ED. L.]

\section{NEUROLOGICAL FRAGMENTS.}

By J. HUGHLINGS JACKSON, M.D. ST. AND., F.R.S., CONSULTING PHIYSICIAN TO TYE LONDON HOSPIIAL AND PHYSICIAN TO THE HOSPI'AL FOR THE PARALYSED AND EPILEPTIC. (Continued from The LANCET of Jan. Ind, 139\%.)

\section{No. XVIII}

ON ASPhyxia iN SLIGHT EPILEPTIC PAROXYSMS.-ON THE SYMPTOMATOLOGY OF SLIGHT EPILEPTIC FITS SUPPOSED TO DEPExD ON DISCHARGE-LESIONS OF THE UNCINATE GYRUS.

IN severe fits of epilepsy there is arrest of respiration from spasmodic fixation of the chest and perhaps there is spasm of the diaphragm also. In some slight epileptic attacks, les petits maux, the patient "turns blue" or "purple"; he may become livid, a "dark pale," to use the expression of the friend of a patient of mine. I have until recently thought that asphyxia in slight fits is owing to spasmodic fixation of the chest and have indeed supposed that some slight fits with asphyxia and without true convulsion of the arms were respiratory (bulbar) fits owing to discharges beginning in the respiratory centre. Certain researches by $\mathrm{Mr}$. W. G. Spencer ("The Effect Produced upon Respiration by Faradic Excitation of the Cerebrum in the Monkey, Dog, Cat, and Rabbit"), ' make me think that another explanation of asphyxia in slight epileptic fits or at least in a certain group of them, is more likely. In this note I only refer to that part of Mr. W. G. Spencer's researches which deals with arrest of respiration. On p. 629 op. cit. Mr. W. G. Spencer writes : "It has, therefore, been shown that the respiration can be slowed and arrested by excitation of a certain spot and a limited area around it. This spot is situated in all the animals examined to the outer side of the olfactory tract just in front of the junction of the tract with the uncinate. And this arrest can be constantly obtained and the experiment repeated again and again under certain conditions." On p. $628 \mathrm{Mr}$. W. G. Spencer writes: "The arrest in the monkey was nearly always in expiration, but only rarely was any active expiration seen." "

I presume that the arrest is by great cortical inhibition of the respiratory (medulla) centre; a superior centre of the lowest level. ${ }^{3}$

I have several times ${ }^{4}$ drawn attention to what I will now call a group of cases of epilepsy-cases in which there is at the onset of the paroxysms a crude sensation of smell or of taste or in which there are movements of chewing, smacking of the lips, and sometimes spitting, \&c. These movements are the indirect, the "reflex," consequences of an epileptic discharge of gustatory elements of the cortex. In some cases of this group there is a warning by what is known as the epigastric sensation; this sometimes occurs along with one of the other crude sensations or with the chewing, \&c., movements. The representation of smell and taste is, according to Ferrier, in the uncinate gyrus; excitation of this gyrus in the animals he experimented on produces, he found, "reflex" movements analogous to those just mentioned as occurring at the onset of certain slight epileptic fits in the human subject. ${ }^{\overline{-}}$ Different varieties of this group

\footnotetext{
1 Transactions of the Royal Society, vol. clxxxv., 1894, B., pp. 609 to 657 .

$2 \mathrm{By}$ the latter part of the quotation is meant a degree of expiration in excess of the normal.

3 THE LANCET, Feb. 23rd, 1895: On Superior and Subordinate Centres of the Lowest Level.

1 Medical Times and Gazette, vol. i., 1879 ; Brain, July, 1880 ; July, 1888 ; and (with Dr. Beevor) Brain, October, 1889

5 I have had under my care a patient who had slight epileptic fits (he had severe attacks too) which began by his making such mouth movements as I have mentioned in the text; no crude sensation of taste was remembered by the patient on coming round from his seizures there was the drea the patient on coming round from his seizures: small focus of softening in the left uncinate gyrus.
}

of cases depend, I suppose, on discharge lesions of different parts of the uncinate gyrus or of parts of convolutions in its close neighbourhood. As will have been inferred it is supposed that in this cortical region are the physical bases of some systemic sensations - to speak very roughly of those systemic sensations especially appertaining to the digestive system.

There is very often the Dreamy State in cases of this group of epileptic fits-the Uncinate Group.

I have had very few opportunities of watching patients in slight paroxysms of epilepsy with regard to degrees of asphyxia. In slight attacks of the group of cases just spoken of there is sometimes "turning blue," as the friends may say. Here comes, I submit, the importance of that part of Mr. W. G. Spencer's research which I have quoted; his "arrest centre" is very near to the uncinate gyrus. So that if an epileptic discharge does begin in some part of that gyrus it may spread to and may soon reach the "arrest centre" : I say "may spread to and may soon reach" because no doubt the degree of spreading and range attained by an epileptic discharge depends on the initial discharge-on the degree of fulmination of the discharge-lesion (quantity of energy liberated and rate of liberation). I suggest particular inquiry and careful observation regarding degrees of asphyxia in slight paroxysms of the group of cases of epilepsy I am dealing with; the colour of the face (especially of the lips), the state of the chest walls and abdomen, and the attitude of these parts, inspiratory or expiratory. Besides this, I ask a question which is, I think, of great importance: Can a considerable degree of asphyxia occur in a slight fit without spasm, real convulsion, I mean tonic or clonic, of the arms? (I am not meaning that slight and yet true spasm of the hand (fingers) may not be present when the rest of the arm is not convulsed.) It is to be urged that on arrested respiration in slight fits there may be writhing movements of the arms, and no convulsion properly so.called of them. The writhing movements are presumably an indirect consequence of (the physical condition for) suffocation.

The following case will serve to illustrate what I have just said. A man, F. F-, aged fifty-two years, had a "funny feeling" which was not true vertigo; of this feeling he said, "I can't tell what it is." I could not be sure it was the dreamy state; very likely it was not, at least not a definite one as in this patient's case I asked leading questions on the matter. His wife knew when his attacks were coming on by a noise he made; she smacked her lips as if tasting to let me know what the noise was. When this noise stopped the patient (his lips) "turned blue"; his eyes were half closed. His arms dropped soft, not stiff. When he came round he "dren a long breath" and began to breathe easily and then seemed "dazed and muddled" and " asked unlikely questions." In this case there was some kind of abnormal affection of taste after the attack; he told me that he had after the attacks a peculiar taste in his mouth, "everything nasty," everything tasted alike; he had complained of this to his wife.

Smacking movements of the lips, nasty taste, dreamy state, if there was one, and "turning blue" may seem at first glance to have no sort of relation to one another. I submit that they have an association in the sense that there is one discharge-lesion of some cells of the uncinate gyrus and that there is spreading of the discharge from this focus. I believe. too, that the dreamy state (which as I have said often occurs in this group of fits although perhaps not in the case of F. F- just narrated) is a consequence, a very indirect consequence, of a discharge-lesion so seated. On looking up my notes of this case I was much interested in the observation of the patient's wife that in the paroxysms his arms were soft, not stiff; it seems that there was asphyxia without any convulsion of these limbs. I will, however, refer to the case of a boy, ten years of age, recorded by Herpin in his valuable work on Epilepsy published in 185\% (p. 275), with regard to the arms in epileptic asphyxia and to several other matters of importance in the analysis of the symptomatology of epileptic fits.

Herpin says that the boy's parents included under the head of vertigo two varieties (I should use the term degrees) of incomplete fits (slight fits). There is no mention of a dreamy state; it is the kind of case in which I should expect there to be one. The boy had also severe attacks ${ }^{6}$ which were always preceded by the incomplete attacks.

"At the beginning of the more severe seizures [the severer of the two degrees of incomplete attacks is meant], which 